\title{
Strategic Implications of COVID-19: Considerations for Georgia's Rural Health Providers
}

Bettye A. Apenteng, $\mathrm{PhD}^{1}$, Linda Kimsey, $\mathrm{PhD}^{1}$, Charles Owens, $\mathrm{MSA}^{1}$, Samuel T. Opoku, $\mathrm{PhD}^{1}$, Angela Peden, $\mathrm{MPH}^{1}$, and William A. Mase, $\mathrm{DrPH}^{1}$

${ }^{1}$ Center for Public Health Practice \& Research, Jiann-Ping Hsu College of Public Health, Georgia Southern University, Statesboro GA.

Corresponding Author: Dr. Linda Kimsey • Georgia Southern University • P.O BOX 8015, Statesboro, GA, 30460-8015 • Telephone: (912) 478-2008 • Email:

1kimsey@georgiasouthern.edu

\section{ABSTRACT}

Whether rural hospitals and providers have seen a surge in COVID-19 cases or a reduction in patients seeking care since the pandemic began, their financial condition has been negatively impacted. Many providers have now received some emergency funding through the Coronavirus Aid, Relief, and Economic Security Act and the Payroll Protection Program but these are likely only short-term fixes. For many, the crisis has exacerbated already existing problems. Notable among these problems are volume declines, supply chain disruptions, and workforce concerns. While these problems require immediate action, two longer-term systemic changes to rural healthcare delivery are needed to address them. Proactive adoption of telehealth is essential to stake a value-added position in delivery of healthcare. Creating a regional ecosystem that both supports, and receives support from, local businesses and potential workforce members is vital to building and maintaining a thriving organization. Rural healthcare providers must consider these strategies to ensure that they are able to continue delivering their mission of improving the health of the populations they serve.

Keywords: COVID-19, rural healthcare, strategic planning, telehealth, ecosystems.

\section{HEALTH CARE PRACTICE POINTS}

- COVID-19 has exacerbated problems of reduced patient volumes, supply chain disruption, and workforce inconsistencies for rural health providers.

- Participation in systems-based strategies focused on creating value for patients, providers, and supporting businesses could be a viable approach for rural health providers.

- Proactive involvement in telehealth networks and development of regional business ecosystems are two strategies for rural health providers to consider.

\section{INTRODUCTION}

The COVID-19 pandemic has taxed the resources and capacity of the nation's healthcare system. Rural healthcare providers, many of which were already struggling financially prior to the pandemic, may be impacted even more significantly. As of October 2020, $98.8 \%$ of rural counties had reported at least one confirmed case of COVID-19, and $79.5 \%$ of rural counties had reported at least one death (Ullrich \& Mueller, 2020). During the spring of 2020, data indicated that the fastest rate of increase in COVID-19 cases and deaths was occurring in rural counties (Kaiser Family Foundation, 2020). While some rural providers have been overtaxed in COVID-19 hotspots, others have lost business as patients delayed non-COVID-19 care out of fear, and as providers paused elective services in preparation for the unknown. Amid this uncertainty, experts continue to worry about the long-term effects of COVID-19 on rural America, where residents on average are older, have more chronic health concerns, and experience more healthcare access-related issues (Centers for Disease Control and Prevention, 2020).

\section{IMPACT OF COVID-19 PANDEMIC ON RURAL HEALTH PROVIDERS}

Whether they saw a surge in COVID-19 cases or not, rural hospitals and providers nationwide have been impacted financially as a result of the pandemic (Arnos \& Blavin, 2020). Many providers received some emergency funding through the Coronavirus Aid, Relief, and Economic Security (CARES) Act and the Payroll Protection Program but these are likely only short-term fixes (U.S. Department of Health and Human Services, 2020; Guelich \& Majka, 2020). Amid this crisis, several multi-faceted factors have arisen that are increasing financial stress. Notable among them are volume declines, supply chain disruptions, and workforce concerns (Arnos \& Blavin, 2020). While these problems require immediate action, longer-term systemic changes to rural healthcare delivery are also needed to fully address them.

\section{Declines in Volume}

As hospitals and clinics halted elective procedures and patients postponed seeking health services, healthcare providers nationwide began experiencing significant declines in volume. In June of 2020, the American Hospital Association (AHA) estimated that by December 2020, hospitals collectively lost over $\$ 323$ billion as a result of the 
pandemic (American Hospital Association, 2020), with some hospitals reporting as much as $50-60 \%$ volume decline (Dineen, 2020). A recent survey identified similar declines in medical practice volume (Medical Group Management Association, 2020). While many hospitals have experienced spikes in COVID-19 related cases, hospital non-COVID-19 volumes continue to struggle to recover back to pre-pandemic levels as patients continue to delay seeking regular and elective care (Grimm, 2021), and these challenges have been particularly hard for rural hospitals over the course of the pandemic (The Duke Endowment, 2020).

The greatest declines in volume have been observed for outpatient and emergency room visits, compared to inpatient services, even in communities not significantly impacted by the virus (Strata Decision Technology, 2020). In Georgia, rural hospitals have also reported significant drops in outpatient volume due to COVID-19 (Weber, 2020). While hospitals (both rural and urban) have over time shifted to the provision of more outpatient services, rural hospitals' growing and disproportionate reliance on outpatient services for revenue leave them particularly vulnerable to financial distress in these times. In 2019, the median outpatient revenue as a proportion of total hospital revenue was $76 \%$ for rural hospitals, compared to $55 \%$ for urban hospitals (Figure 1). While Georgia rural hospitals rely less on outpatient services, relative to all US rural hospitals, the median outpatient to total revenue for Georgia rural hospitals still remains higher than urban hospitals in the state and nationally (Figure 1). Thus, building outpatient service volume back to pre-COVID-19 levels (and beyond) would be imperative for sustainability of both Georgia and national rural hospitals, and may require a concerted effort by healthcare providers to build public confidence in the safety of healthcare facilities.

Figure 1

\section{US Hospitals' Dependence on Outpatient Services}

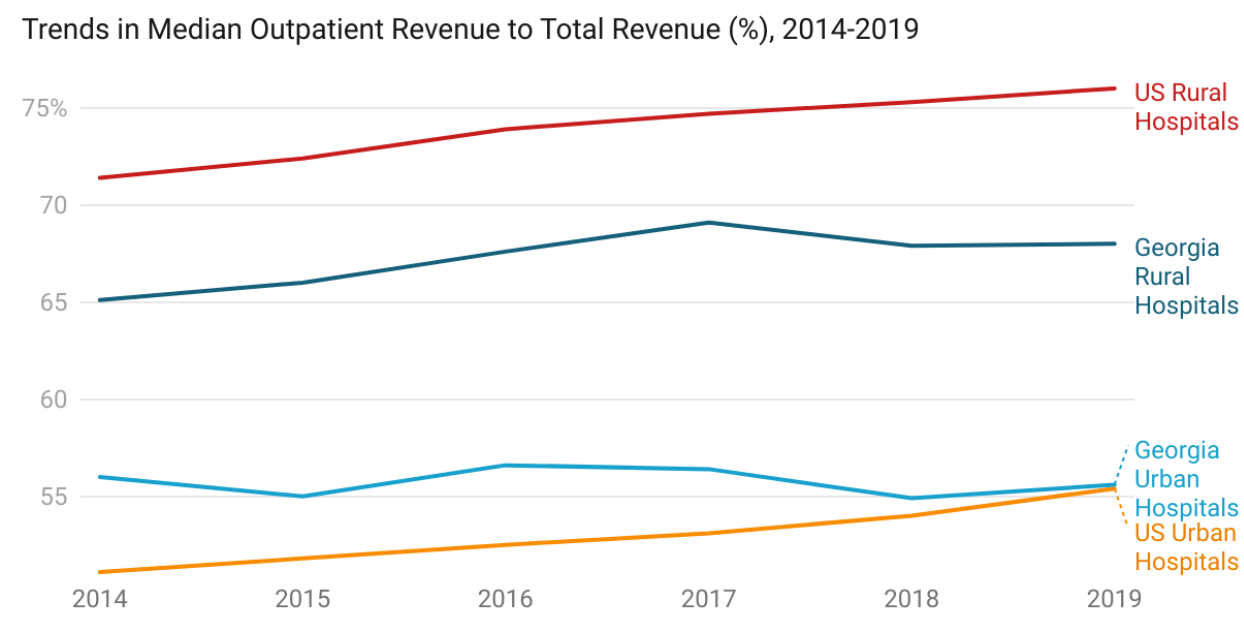

Authors' analysis of data from the Medicare Hospital Cost Reports, (Fiscal Year 2014-2019). Hospitals located in counties that are not part of a Metropolitan Statistical Area (MSA) are considered rural.

\section{Supply chain disruptions}

The pandemic has also uncovered healthcare supply chain vulnerabilities. Disruptions in the manufacturing of goods in the wake of the pandemic, coupled with excessive demand, resulted in shortages of medical supplies and subsequent increases in the prices of medical supplies. One supply category that took on added importance as a result of the pandemic was personal protective equipment (PPE). Many rural hospitals and providers, including those in Georgia, struggled to obtain PPE and other similar items needed to respond to the pandemic (Miller, 2020).

Responses to shortages of medical supplies have displayed ingenuity. Nationally, several hospitals had to bypass their group purchasing organizations (GPOs) and other intermediaries and directly source their supply needs for the first time (Kaste \& Ruwitch, 2020). In Georgia, Pretoria Fields Collective, an Albany-based brewery, converted its factory line to produce medical supplies for their local hospital and other rural hospitals (Carter, 2020). Early in the pandemic, "outside of the box" strategies by rural hospitals to shore up supplies of required equipment, like Homerville Georgia-based Clinch Memorial Hospital's use of staff with sewing skills to make cloth masks (Weber, 2020), were highlighted throughout the news.

Prior to COVID-19, hospitals had begun to embrace the Lean operational improvement philosophy, and inventory systems such as Just-in-Time (JIT), which minimize 
inventories held, to reduce waste and lower costs (Snyder \& McDermont, 2020). However, the COVID-19-related shortages suggest a need to advance these JIT efforts more strategically - recognizing the importance of slack and higher levels of "just in case" inventories (Sheffi, 2020). Lessons learned pertaining to the need for supply chain diversification, refined supply chain processes, and enhanced innovation to improve resiliency will likely be analyzed for years to come.

\section{Workforce concerns}

Maintaining a skilled healthcare workforce is a persistent challenge nationally, and COVID-19, with its accompanying surges and lulls in workload, has only heightened that challenge. In preparation for potential surges in COVID-19 cases, and amidst existing shortages, many rural (and urban) healthcare organizations had to develop creative approaches for staffing. Some hospitals, for example, created a workforce resource pool, including retirees, administrators, and educators, to fall back on when the need arises (Muller, 2020). Yet other hospitals found themselves going through periods of reduced workload. In rural healthcare organizations that experienced financial losses due to low volume in the early stages of the pandemic, and struggled to make payroll, staff recruitment became a lower priority. Instead, these organizations implemented layoffs and furloughs to manage financial viability (Grimm, 2020).

The evidence further suggests that the multiple waves of the pandemic have taken a significant physical and psychological toll on healthcare workers. As of April 14th 2021, the Centers for Disease Control and Prevention reported that over 463,000 health care workers had been infected with COVID-19 and almost 1,200 died from the disease (Centers for Disease Control and Prevention, 2021). A recent study conducted by Kaiser Health News, in partnership with the Guardian, estimated more than 3,600 healthcare worker deaths nationally as of April 7, 2021, a majority of which occurred among individuals under 60 years, nurses, and people of color (KHN \& The Guardian, 2021). For Georgia, the healthcare worker toll from COVID-19 is estimated to be 38,881 cases (Georgia Department of Health, 2021) and 74 deaths (KHN \& The Guardian, 2021) as of mid-April 2021. Recent studies also indicate high levels of anxiety and depressive symptoms and burnout among healthcare workers responding to the pandemic, especially among those who have contracted the virus or have had a coworker contract the virus (Firew et al., 2020).

The workforce-related challenges brought on by COVID-19 have been especially difficult for Georgia hospitals. In December 2020, Georgia hospital CEOs told Governor Kemp that personnel shortages were their most significant COVID-related problem (Miller, 2020b). Rural Georgia hospitals that might have had physical bed capacity, often found that they did not have the necessary personnel (in particular, ICU nurses) to make those beds operational, forcing patient transfers to other cities (Miller, 2020a). However, these struggles merely exacerbated existing workforce challenges for rural Georgia hospitals. Attracting and retaining qualified personnel has been particularly difficult for rural areas, even before the pandemic. Several of Georgia's rural counties have no physician providers (Spelke et al., 2016; Sweeney, 2016) and shortages of nursing professionals are projected to grow to 2,200 across the state by 2030 (U.S Department of Health and Human Services, 2017).

The full workforce impacts of the pandemic are yet to be revealed. However, some potentialities include a worsening of existing rural workforce shortages due to voluntary retirement or turnover driven in part by burnout and safety concerns, and attrition due to elevated mortality from COVID-19 spikes that could occur within the workforce.

\section{RELEVANT SYSTEMS LEVEL STRATEGIES}

None of these issues will likely resolve any time soon; long-term strategic implications post-COVID-19 should be expected. The current overall economic downturn may reshape the healthcare market considerably. Rural healthcare organizations will need to be prepared to deal with these potential long-term implications in order to remain viable. What is certain is that thinking at a systems level - beyond the organization, and in consideration of other actors that share its goals - will be increasingly important as the complex adaptive system of healthcare grows even more complex, with or without COVID-19. While many rural hospitals have become part of larger health systems, this should not be assumed to be a panacea to the woes that COVID-19 has accentuated: these health systems may have little economic tolerance for supporting unprofitable satellite members in a financially challenging environment that the pandemic has created. Securing a position in other systems or networks will be essential. Two systems-level strategies that may be helpful for rural healthcare providers seeking to thrive in the future are telehealth adoption and building regional ecosystems.

\section{Telehealth}

The pandemic has created an environment that has opened the door for many providers to adopt telehealth as a means of providing essential healthcare in a way that significantly reduces patient, provider, and staff exposure to the virus. A system that allows for local healthcare to continue with minimal disruption is vital for the health of the community and the financial sustainability of an already fragile healthcare system. Telehealth has proven to be an essential tool for improving healthcare access, maintaining continuity of care, and enhancing financial sustainability during the pandemic. Analysis of telehealth usage from June 26 to Nov 6, 2020 indicates a direct correlation between the amount of telehealth visits and the number of COVID-19 cases (Demeke et al., 2021). Without telehealth, pandemic-driven social distancing guidelines and public worry might have limited health care providers' capacity to provide timely and accessible care, leaving massive gaps in healthcare access. Rural hospitals and clinics, too, must embrace telehealth as a means of extending the workforce and retaining higher 
acuity patients within the community by facilitating connections to specialists in neighboring communities.

COVID-19 has positioned telehealth as a cornerstone of health care delivery and has strengthened rural and urban hospitals working together to meet the needs of their communities wherever they live. Just before COVID-19 appeared in Georgia, rural Wills Memorial Hospital implemented telehealth as part of a program with Augusta University (AU) to leverage AU physicians to support their patients in need of care beyond what is available locally. Patients connect virtually allowing the patient and physician provider to communicate directly with one another to evaluate and determine the most appropriate care needed. Patients are treated without unnecessary transport (55 miles each way), additional costs or stress occurring from having to be transported to Augusta. AU, like most urban hospitals, has been operating at or near capacity since COVID-19 appeared. Telehealth allows AU physicians to evaluate and treat patients at Wills Memorial virtually. This, in turn, allows the patient to receive the appropriate care close to home and saves critically low bed space for those in greatest need. Additionally, it allows the rural hospital that is providing care to earn revenue that might have otherwise been lost (The Augusta Chronicle, 2020).

Wills Memorial Hospital's pre-pandemic telehealth focus is an illustration of an increasing trend in the uptake of telehealth by Georgia's rural hospitals. Between 2017 and 2019, the proportion of Georgia's rural hospitals utilizing telehealth for consultations and office visits tripled from approximately $15 \%$ to $46 \%$, surpassing rural hospitals in other states (Figure 2). The pandemic-driven increase in provider adoption and patient willingness to use telehealth is likely to be sustained in the post-pandemic era (Thomas et al., 2020).

Figure 2

\section{Use of Telehealth for Consultation and Office Visits in US Hospitals}

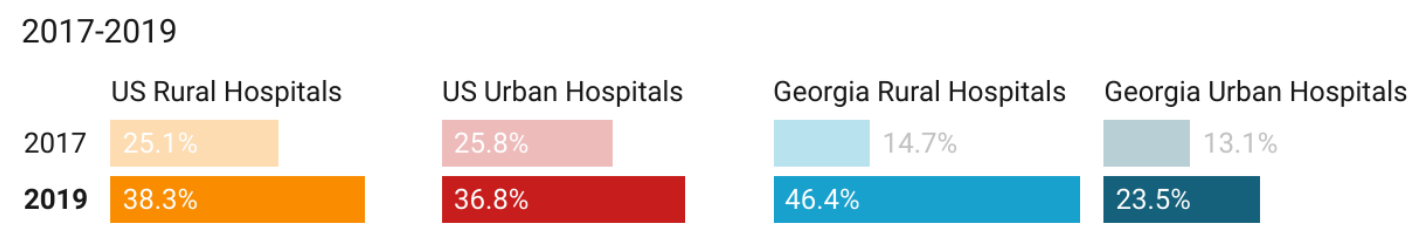

Authors' analysis of data from the American Hospital Association Annual Survey (2017 \& 2019). Hospitals located in counties that are not part of a Metropolitan Statistical Area (MSA) are considered rural.

Created with Datawrapper

To aid in encouraging telehealth within the healthcare system, the CARES Act expanded coverage of telehealth services for Medicare patients and among safety net providers including Rural Health Clinics, Federally Qualified Health Centers, among others (Centers for Medicare and Medicaid Services, 2020a; Centers for Medicare and Medicaid Services, 2020b). On December 1st 2020, the Centers for Medicare and Medicaid Services announced that it was making permanent coverage for over 60 out of the 144 telehealth services that were newly covered in response to the pandemic (Centers for Medicare and Medicaid Services, 2020c).

Although telehealth brings with it increased privacy concerns, it is likely the new normal. Proactively adopting telehealth will be essential for rural healthcare providers as they address declining patient volumes and workforces that have been stretched thin. However, the success of telehealth in effectively expanding healthcare access, especially in rural areas, will depend on the existence of robust infrastructure to support its implementation, such as broadband internet services, the willingness of rural residents and providers to use telehealth services, and an alignment of reimbursement models (Haque, 2021).
Telehealth usage in both the south and in rural areas of the U.S. was found to lag that of the rest of the country during the pandemic (Demeke et al., 2021), indicating that the south, including Georgia, may find it more challenging to embrace virtually-delivered healthcare.

\section{Ecosystems}

Supply chains that run from China to rural America have now become common in many business sectors, including rural healthcare. Likewise, the use of more costly per diem, travel, and locum tenens healthcare personnel has increased and is forecast to increase even more in the post-COVID-19 era (Staffing Industry Analysts, 2020). Given the supply chain and workforce issues discussed above that have been exacerbated by COVID-19, an overreliance on these strategies now seems possibly shortsighted. Providing support for local and regional businesses and potential workforce members is a long-term, systems-based strategy that aligns with healthcare's overarching mission to support its community and could also serve to enhance organizational resilience. 
The AHA's Healthcare Innovation blog, pre-COVID-19, discussed the possibility of "ecosystem" becoming the new healthcare buzzword (Shin, 2019). A service ecosystem is a "relatively self-contained, self-adjusting system of resource-integrating actors connected by shared institutional arrangements and mutual value creation through service exchange" (Vargo \& Lusch, 2016, p.11). In a service ecosystem, value is achieved at a system level through exchange among its actors, and improved system viability is one way to improve value ( $\mathrm{Ng} \&$ Vargo, 2018). Essentially, ecosystems are about integrating internal and external stakeholders to facilitate innovative and responsive organizational growth (Shin, 2019).

Looking through the COVID-19 lens, a service ecosystem strategy, in which hospitals serve as anchor institutions for the community, seems to be a possibly fruitful strategy. Anchor institutions seek to merge mission and margin, acknowledging their leadership role in the local community in which they operate. In urban areas, these hospitals are often located near the communities of greatest need, serving to motivate a focus on improving social determinants of health (Koh et al., 2020). These hospitals are also typically one of the five largest employers in their community, and they have substantial budgets for supplies and services. For example, Cleveland Clinic's commitment to buy local has been attributed to the founding of several successful worker-owned cooperative businesses (Koh et al., 2020). Brigham and Women's hospital is committed to training local residents for employment within their health system (Zuckerman, 2013). Similarly, Kaiser Permanente and Promedica are also undertaking anchoring initiatives in the areas they serve (Koh et al., 2020). While scaling this type of ecosystem down to small hospitals and communities is yet unproven, regional collaboratives of hospitals, clinics and communities, all seeking these same goals of reliable supply chains, an available, qualified workforce, and a thriving community in which to provide healthcare, might be possible. A newly formed cooperative arrangement, connecting small rural hospitals and Georgia farmers to provide locally-farmed produce and meat in hospital cafeterias, is one example of this type of ecosystem strategic approach now underway in Georgia (Gibson, 2020).

\section{Systems Focus}

What telehealth and ecosystems-focused strategies have in common is a requirement for healthcare providers to secure their position within developing systems. Developing a strong value proposition for local residents to ensure that they continue seeking care locally will be important. With in-home telehealth encounters now covered by insurance, there could be a risk of losing patients to providers in nearby large cities, since specialist appointments can be provided directly, bypassing local providers. Maximizing other opportunities of telehealth through things like robust use of shared grand rounds and other employee training will also be important. An active educational network of providers who face similar clinical issues on which to learn from, can increase the benefits reaped from telehealth capabilities. Similarly, for ecosystem development, staking a position within a healthy ecosystem will be important. Creating a vibrant marketplace that supports co-production of health by training and maintaining a qualified workforce and by supporting companies that provide supplies, equipment, and services can cure the fragility that comes with 10,000-mile-long supply chains and markets for graduates of distant schools. In return, local and regional residents gain financial security and career advancement, improving the chances of a thriving ecosystem. Finally, development of regional networks and systems may offer small, rural hospitals and healthcare facilities the potential for achieving meaningful operational economies of scale in maintaining productive workforces and procuring needed supplies and services.

\section{CONCLUSION}

COVID-19 may come to be known as a black swan event like no other, due to its global, enduring impact. As we recover from this unprecedented event, rural healthcare administrators must move forward strategically to tackle volume, supply chain, and workforce issues laid bare by COVID-19. Establishing an environment where telehealth is deployed across the continuum of care for financial stability and care continuity and creating supportive local and regional ecosystems are two systems-level strategies worth considering as rural providers strive to address these issues and secure their future.

\section{Methodology for Supporting Figures}

Data from Figures 1 and 2 were obtained from the Centers for Medicare and Medicaid Services Cost Reports (2014-2019) and the American Hospital Association's Annual Hospital Survey (2017 and 2019), respectively. Descriptive statistics (medians and proportions, respectively) are used to assess trends in hospital dependence on outpatient services (Figure 1) and telehealth use (Figure 2). Aggregate data were obtained for Georgia, and the United States as well as for rural and urban counties. Hospitals located in Metropolitan Statistical Areas (MSAs) were classified as urban. Hospitals located in counties not part of an MSA were classified as rural.

\footnotetext{
References

American Hospital Association. (2020). Hospitals and health systems face unprecedented financial pressures due to COVID-19. Retrieved June 15, 2020, from https://www.aha.org/guidesreports/2020-05-05-hospitals-and-he alth-systems-face-unprecedented-financial-pressures-due

Arnos, D. \& Blavin, F. (2020, April 6). To weather COVID-19, rural hospitals might need more support. Retrieved June 22, 2020, from

https://www.urban.org/urban-wire/weather-covid-19-rural-hospit als-might-need-more-support

Carter, A. (2020, March 26). Rural Georgia Businesses Shift to Making Critical Medical Supplies.

https://www.georgia.org/newsroom/blogs/rural-georgia-business es-shift-making-critical-medical-supplies
} 
Centers for Disease Control and Prevention. (2017, August 2). Rural health. CDC. Retrieved June 22, 2020, from https://www.cdc.gov/ruralhealth/about.html

Centers for Disease Control and Prevention. (2021, April 14). CDC COVID Data Tracker. CDC. Retrieved April 14, 2021 from https://covid.cdc.gov/covid-data-tracker/\#health-care-personnel

Centers for Medicare and Medicaid Services. (2020a, March 17).

Medicare Telemedicine Health Care Provider Fact Sheet. CMS

Newsroom. Retrieved June 2, 2020, from

https://www.cms.gov/newsroom/fact-sheets/medicare-telemedici ne-health-care-provider-fact-sheet

Centers for Medicare and Medicaid Services. (2020b). New and Expanded Flexibilities for Rural Health Clinics (RHCs) and Federally Qualified Health Centers (FQHCs) During the COVID-19 Public Health Emergency (PHE). Retrieved June 2, 2020, from https://www.cms.gov/files/document/se20016.pdf

Centers for Medicare and Medicaid Services. (2020a, December 1). Trump Administration Finalizes Permanent Expansion of Medicare Telehealth Services and Improved Payment for Time Doctors Spend with Patients. Retrieved January 1, 2020 from https://www.cms.gov/newsroom/press-releases/trump-administra tion-finalizes-permanent-expansion-medicare-telehealth-services -and-improved-payment

Dineen, H. (2020, April 24). Maine hospitals losing \$250 million per month during coronavirus, COVID-19 pandemic. Retrieved June 20, 2020, from

https://www.newscentermaine.com/mobile/article/news/health/m aine-hospitals-losing-250-million-per-month-during-covid-19-pa ndemic/97-8e4aa312-3312-4b25-bed4-dd9311e7e489

Firew, T., Sano, E. D., Lee, J. W., Flores, S., Lang, K., Salman, K., ... \& Chang, B. P. (2020). Protecting the front line: a cross-sectional survey analysis of the occupational factors contributing to healthcare workers' infection and psychological distress during the COVID-19 pandemic in the USA. BMJ open, 10(10), e042752.

Georgia Department of Public Health. (2021, April 14). Daily

Status Report. Retrieved April 14, 2021 from

https://dph.georgia.gov/covid-19-daily-status-report

Gibson, DM. (2020, May 25). HomeTown Health organizes Georgia grown produce \& meats to Rural Hospital kitchens, with key agriculture leaders \& rural hospital leaders. Retrieved December 8, 2020 from

https://www.hometownhealthonline.com/hometown-health-orga nizes-georgia-grown-produce-meats-to-rural-hospital-kitchenswith-key-agriculture-leaders-rural-hospital-leaders/

Grimm, C. (2020). Hospital Experiences Responding to the COVID-19 Pandemic: Results of a National Pulse Survey March 23-27, 2020. Retrieved June 2, 2020 from

https://justthenews.com/sites/default/files/2020-04/HHS2020Re portPandemicHospitals.pdf

Grimm, C. A. (2021). Hospitals Reported That the COVID-19

Pandemic Has Significantly Strained Health Care Delivery. US

Department of Health \& Human Services. Office of the

Inspector General.

https://oig.hhs.gov/oei/reports/OEI-09-21-00140.pdf

Guelich. K. \& Majka, D. (2020). COVID-19 and a new financial perspective for hospitals. Kaufmann Hall. Retrieved May 31, 2020, from

https://www.kaufmanhall.com/ideas-resources/article/covid-19-a nd-new-financial-perspective-hospitals

Haque, S. N. (2021). Telehealth Beyond COVID-19. Psychiatric Services, 72(1),100-103

Kaiser Family Foundation. (2020, April 23). COVID-19 in rural America - Is there cause for concern? Retrieved June 23, 2020, from

https://www.kff.org/other/press-release/covid-19-in-rural-americ a-is-there-cause-for-concern/
Kaiser Health News \& the Guardian. Lost on the Frontline: US Healthcare. Retrieved April 14, 2021 from

https:/www.theguardian.com/us-news/ng-interactive/2020/dec/2 2/lost-on-the-frontline-our-findings-to-date

Kaste, M. \& Ruwitch, J. (2020, April 21). States and hospitals are sourcing their Own PPEs from China. NPR. Retrieved June 2, 2020 from

https://www.npr.org/2020/04/21/840522657/states-and-hospitals -are-sourcing-their-own-ppe-from-china

Koh, H. K., Bantham, A., Geller, A. C., Rukavina, M. A., Emmons, K. M., Yatsko, P., \& Restuccia, R. (2020). Anchor Institutions: Best Practices to Address Social Needs and Social Determinants of Health. American Journal of Public Health, 110(3), 309-316.

Medical Group Management Association. (2020, April 13). COVID-19 Financial Impact on Medical Practices. Retrieved June 2, 2020 from

https://mgma.com/resources/government-programs/covid-19-fin ancial-impact-on-medical-practices

Miller, A. (2020a, July 21). Rural hospitals face COVID challenges of patient transfers, staffing. Georgia Health News. https:/www.georgiahealthnews.com/2020/07/rural-hospitals-fig ht-covid-related-problems-patient-transfers-staffing/

Miller, A. (2020b, December 3) Georgia Hospitals Say Staffing Crunch Is Biggest Pandemic Challenge. Retrieved January 3, 2021 from:

https://www.wabe.org/georgia-hospitals-say-staffing-crunch-is-b iggest-pandemic-challenge/

Muller, L. (2020, April 06). Deep Concern For Some Iowa Hospitals' Viability After COVID-19 Crisis.

https://www.iowapublicradio.org/health/2020-04-06/deep-conce rn-for-some-iowa-hospitals-viability-after-covid-19-crisis

Ng, I. C., \& Vargo, S. L. (2018). Service-dominant (SD) logic, service ecosystems and institutions: bridging theory and practice. Journal of Service Management, 29(4), 518-520.

Sheffi, Y. (2020, April 10). Commentary: Solving the Health-Care Equipment Supply Shortage. Wall Street Journal. Retrieved June 15,2020 , from

https:/www.wsj.com/articles/commentary-solving-the-health-ca re-equipment-supply-shortage-11586512801

Shin A. (2019). Why 'ecosystems' will be the 2020 leading health care buzzword. American Hospital Association. Healthcare Anchor Network. Retrieved June 2, 2020, from https:/www.aha.org/news/healthcareinnovation-thursday-blog/2 019-11-07-why-ecosystems-will-be-2020-leading-health-care

Snyder, K.D. \& McDermott, M. (2009). A rural hospital takes on Lean. Journal for Healthcare Quality, 31(3), 23-28.

Spelke, B., Zertuche, A. D., \& Rochat, R. (2016). Obstetric provider maldistribution: Georgia, USA, 2011. Maternal and child health journal, 20(7), 1333-1340.

Staffing Industry Analysts. (2020, April 10). US staffing market forecasted to contract by $21 \%$ in 2020 amid uncertainty. Retrieved May 23, 2020, from https://www2.staffingindustry.com/About/Media-Center/Press-R eleases/US-Staffing-Market-Forecasted-to-Contract-by-21-in-20 20-Amid-Uncertainty

Strata Decision Technology. (2020). National Patient and Procedure Volume Tracker. Retrieved June 2, 2020, from https://www.stratadecision.com/National-Patient-and-ProcedureVolume-Tracker/

Sweeney, T. (2016). Prescribing Remedies for Georgia's Medical Provider Shortage. Georgia Budget and Policy Institute. Retrieved on December 30, 2020 from http://gbpi.org/wp-content/uploads/2016/06/Medical-Provider-S hortage.pdf

The Augusta Chronicle (2020, February, 22). Teleconferencing brings AUMC expertise to rural ERs. 
https://www.augustachronicle.com/news/20200222/teleconferen cing-brings-aumc-expertise-to-rural-ers

The Duke Endowment. (2020). One Rural Hospital's Fight Against COVID-19.

https://www.dukeendowment.org/story/one-rural-hospital\%E2\% $80 \% 99$ s-fight-against-covid-19?utm campaign=ENewsStories\& utm_content $=1597272302 \&$ utm_medium $=$ The + Duke + Endowm ent\&utm source $=$ facebook

Thomas, E. E., Haydon, H. M., Mehrotra, A., Caffery, L. J., Snoswell, C. L., Banbury, A., \& Smith, A. C. (2020). Building on the momentum: Sustaining telehealth beyond COVID-19. Journal of Telemedicine and Telecare, 1357633X20960638.

Ullrich, F. \& Mueller, K.(2020). Confirmed COVID-19 cases, metropolitan and nonmetropolitan counties. (Brief Number 2020-2). Retrieved June 23, 2020, from

https://rupri.public-health.uiowa.edu/publications/policybriefs/2 020/COVID\%20Data\%20Brief.pdf

U.S. Department of Health and Human Services. (2020, April 22). HHS awards nearly \$165 Million to combat the COVID-19 pandemic in rural communities. Retrieved June 19, 2020, from https://www.hhs.gov/about/news/2020/04/22/hhs-awards-nearly- 165-million-to-combat-covid19-pandemic-in-rural-communities. html

U.S. Department of Health and Human Services, Health Resources and Services Administration (2017, July 21). Supply and demand projections of the nursing workforce. https://bhw.hrsa.gov/sites/default/files/bhw/nchwa/projections/N CHWA_HRSA_Nursing_Report.pdf

Vargo, SL \& Lusch RF. (2016). Institutions and axioms: An extension and update of service-dominant logic. Journal of the Academy of Marketing Science, 44(1), 5-23.

Weber, L. (2020, March 23). COVID-19 threatens rural hospitals already stretched to breaking point. Modern Healthcare. Retrieved May 24, 2020 from https://www.modernhealthcare.com/providers/covid-19-threaten s-rural-hospitals-already-stretched-breaking-point

Zuckerman, D. (2013). Hospitals building healthier communities. The Democracy Collaborative at the University of Maryland, Report, Retrieved Jan 1, 2021 from https://community-wealth.org/sites/clone.community-wealth.org /files/Zuckerman-HBHC-2013-summary-twopage.pdf

(C) Bettye A. Apenteng, Linda Kimsey, Charles Owens, Samuel T. Opoku, Angela Peden, and William A. Mase. Originally published in jGPHA (http://www.gapha.org/jgpha/) May 15, 2021. This is an open-access article distributed under the terms of the Creative Commons Attribution Non-Commercial No-Derivatives License (http://creativecommons.org/licenses/by/4.0/), which permits unrestricted use, distribution, and reproduction in any medium, provided the original work ("first published in the Journal of the Georgia Public Health Association...") is properly cited with original URL and bibliographic citation information. The complete bibliographic information, a link to the original publication on http://www.gapha.jgpha.org/, as well as this copyright and license information must be included. 